\title{
FILTRAÇÃO LENTA PARA O TRATAMENTO DE ÁGUAS PARA PEQUENAS COMUNIDADES RURAIS
}

\section{SLOW FILTRATION FOR THE WATER TREATMENT FOR RURAL SMALL COMMUNITIES}

\author{
Ana Paula do Nascimento ${ }^{1}$, Ronaldo Teixeira Pelegrini ${ }^{2}$, Núbia Natália de Brito ${ }^{3}$
}

Recebido em 16 de agosto de 2012; recebido para revisão em 18 de agosto de 2012; aceito em 23 de agosto de 2012; disponível on-line em 31 de agosto de 2012.

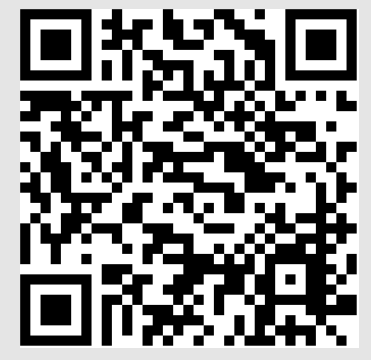

\section{PALAVRAS CHAVES:}

Filtração lenta;

Tratamento de água;

Filtro de areia;

\section{KEYWORDS:}

Slow filtration;

Water treatment;

Sand filter;

\footnotetext{
* Contato com os autores:

${ }^{1}$ e-mail : anapaulanascimento83@yahoo.com.br (A. P. do Nascimento)

Aluna de Iniciação Científica da Universidade Federal de São Carlos - UFSCAR. Centro de Ciências Agrárias.

22e-mail : ronaldopelegrini@gmail.com (R. T. Pelegrini)

Prof Dr da Universidade Federal de São Carlos- UFSCAR Centro de Ciências Agrárias

${ }^{3}$ e-mail : nubiabrito@quimica.ufg.br (N. N. De Brito)

Profa. Dra. da Universidade Federal de Goiás - UFG. Instituto de Química.
}

ABSTRACT: This work had as objective the construction and the evaluation of a slow filter in scale laboratorial used sands and non-woven synthetic fabrics seeking the water treatment for rural communities small using for this, simple materials and of low cost. The $\mathrm{mm}$ layer ollowed by breaks $100 \mathrm{~mm}$. Among the described layers and in the top nonwoven synthetic fabrics were used with $400 \mathrm{~g} / \mathrm{m}^{2}$ grammage. The filtration rate adopted (CO) seeking the monitoring of the water of a pond inside of the Campus- Center of Agrarian Sciences (CCA-UFSCAR). The principal found results were: $\mathrm{pH}$ value 7,0 $\pm 0,07$, of turbidity reduction, $50 \%$ of coloration reduction, $50 \%$ of organic matter reduction good conditions, getting to accomplish the important minerals cycle and slow filter built demonstrates efficiency in the polishing of the pond in study. 


\section{INTRODUÇÃO}

A dificuldade crescente de oferecimento de água de boa qualidade em quantidades suficientes à população é uma preocupação do mundo moderno. No Brasil, muitas vezes não há condições financeiras ou informação suficiente para que haja um tratamento adequado. Como consequência, acontece um grande desperdício de quantidades de água que poderiam ser reutilizadas.

A preocupação das autoridades tem sido abastecer as localidades de maneira isonômica para todas as camadas da sociedade, porém o investimento em estações de tratamento é sempre considerado elevado para comunidades com população de até 1.000 habitantes (Veras e Di-Bernardo, 2008).

A viabilização de projetos de sistemas com grande eficiência para o tratamento de águas tem sido bastante observada, contudo, essas novas tecnologias estão voltadas, sobretudo para o tratamento de grandes volumes de água e para grandes cidades.

Nos principais centros urbanos, em particular nos das regiões sudeste e sul, o solo das bacias hidrográficas apresenta alta densidade demográfica, devido à maior atividade econômica da região e a grande presença de indústrias. A água dos mananciais superficiais dessas bacias quase sempre não apresenta características de água potabilizável. O solo é ocupado, ainda, por propriedades agrícolas que também geram produtos que poluem e contaminam os corpos de água (ou mananciais) superficiais e subterrâneos (Veras e DiBernardo, 2008).

De modo geral, pouca atenção se dá ao tratamento de águas para propriedades rurais. Poucos projetos de tratamento de água propõem desenvolver tecnologias voltadas à população rural. Devido aos problemas apresentados nos mananciais, atualmente vem aumentando o interesse por tecnologias não convencionais, como a filtração lenta. A filtração lenta apresenta a capacidade de remoção de microrganismos, toxinas produzidas por cianobactérias, agroquímicos e matéria orgânica natural, além de apresentar um baixo custo de construção e manutenção e simplicidade de operação.

A filtração lenta é reconhecida como a tecnologia mais apropriada para tratar água para abastecimento de pequenas comunidades por ser de simples construção, operação e manutenção, o que representa custos geralmente acessíveis ao produtor rural.

O presente trabalho teve como objetivo construir um filtro lento e avaliar a eficiência de um sistema de filtração utilizando materiais de fácil obtenção no mercado, como pedregulho e areia comumente usados na construção civil e mantas sintéticas não tecidas.

\section{MATERIAL E MÉTODOS}

$\mathrm{Na}$ avaliação da eficiência do filtro lento foram empregados os seguintes parâmetros: cor, $\mathrm{pH}$, turbidez, fenóis totais e Oxigênio Consumido (OC). Os resultados foram comparados com os parâmetros da Portaria MS 2914 de 2011 que dispõe sobre os procedimentos de controle e vigilância sanitária da qualidade da água para consumo humano e seu padrão de potabilidade.

A coloração verdadeira foi determinada de acordo com o método de comparação de cor utilizandose o reagente Cloro Platinato de Cobalto, que estava nas concentrações de 5, 10, 15, 20, 25 e 30 mg/L. A determinação dos valores de $\mathrm{pH}$ foi realizada de acordo com método potenciométrico utilizando medidor de $\mathrm{pH}$ aferido nos valores padrões de $\mathrm{pH} 4,0 ; 7,0$ e 9,0. A turbidez foi determinada de acordo com o método Nefelométrico. As análises de fenóis totais foram realizadas de acordo com o método colorimétrico fundamentada na reação com o reagente de FolinCiocalteau. A análise de Oxigênio Consumido foi realizada seguindo o método do permanganato de potássio em meio ácido.

Todas as análises foram realizadas de acordo com Standard Methods for the Examination of Water and Wastewater (5220 D), 20th Edition, 1998. A amostra utilizada para avaliar a eficiência do filtro lento construído foi coletada de uma lagoa localizada dentro do próprio Centro de Ciências Agrárias (CCA). Este sistema aquático é artificial proveniente de duas nascentes do próprio campus (CCA), recebe descarga de efluentes líquidos derivados de processo de ordenhamento e é utilizada para irrigação de plantio de cana de açúcar dentro do campus.

As amostras foram coletadas semanalmente no período vespertino entre os anos de 2009 e 2010 . As coletas foram realizadas de acordo com a Norma NBR 9898 da ABNT.

\subsection{Construções do Filtro lento}

O filtro lento foi construído utilizando um tubo cilíndrico de PVC (policloreto de vinila) com altura útil de $1000 \mathrm{~mm}$, diâmetro de $150 \mathrm{~mm}$. A espessura do material filtrante foi constituída de uma camada de 400 $\mathrm{mm}$ de areia seguido de $100 \mathrm{~mm}$ de brita. Entre as camadas descritas e no topo foram utilizadas mantas sintéticas não tecidas com gramatura de $400 \mathrm{~g} / \mathrm{m}^{2}$ (Figuras 1 e 2).

Foi utilizado como material filtrante, além da areia, mantas sintéticas não tecidas da marca Geotêxtil GeoFort GF modelos 14 e 17 denominadas de M1 e M2 respectivamente. A manta $\mathrm{M} 1$ é caracterizada por: Porosidade 93.81\%, superfície especifica de 3,645 $\mathrm{m}^{2} / \mathrm{m}^{3}$, gramatura $300 \mathrm{~g} / \mathrm{m}^{2}$ e espessura de $2 \mathrm{~mm}$. A manta M2 e caracterizada por Porosidade $95.70 \%$, 
superfície especifica de $2,530 \mathrm{~m}^{2} / \mathrm{m}^{3}$, gramatura $400 \mathrm{~g} /$ $\mathrm{m}^{2}$ e espessura de $3 \mathrm{~mm}$. As duas mantas utilizadas na pesquisa são compostas com $100 \%$ de polipropileno.

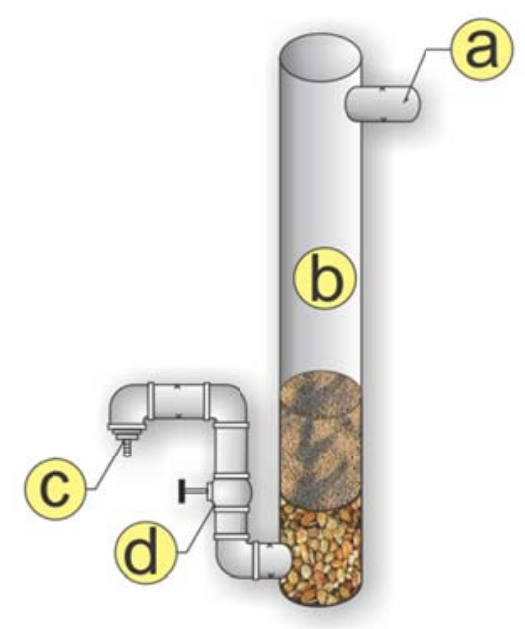
(a) entrada;
(b) sistema de filtração lenta;
(C) saída;
(d) regulador de vazão;

Figura 1: Esquema da instalação piloto do sistema de filtração lenta.

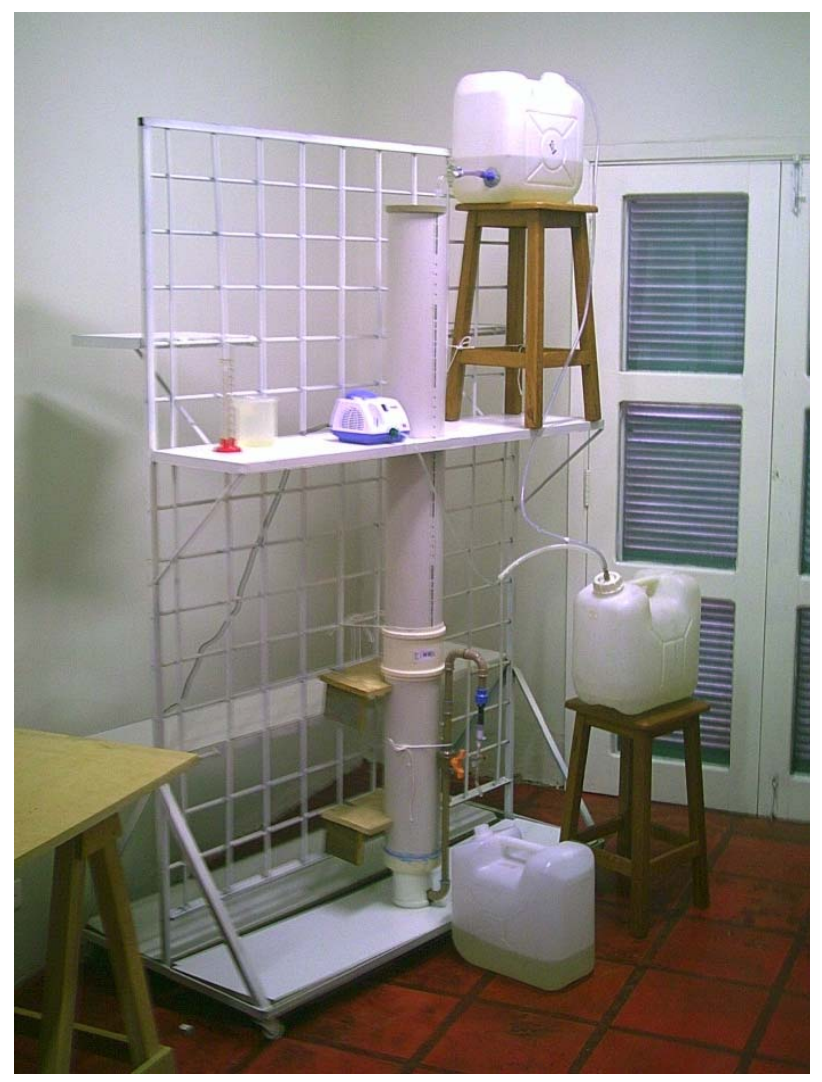

Figura 2: Fotografia do Filtro lento construído.

\section{RESULTADOS E DISCUSSÕES}

\subsection{Valores de $\mathrm{pH}$}

Os ecossistemas sempre estão sujeitos aos impactos provocados pela variação dos valores de $\mathrm{pH}$ da água "in natura" e tratada pela filtração lenta. Muitas bactérias não podem proliferar em níveis de $\mathrm{pH}$ abaixo de 4,0 ou acima de 9,5, sendo que, geralmente, o pH ótimo para o crescimento bacteriano está entre 9,5 e 6,5 (OLIVEIRA, et al., 2008). Neste sentido um estudo rigoroso dos níveis de $\mathrm{pH}$ faz-se necessário para avaliar a viabilidade de vida em qualquer ambiente aquático (Figura 3).

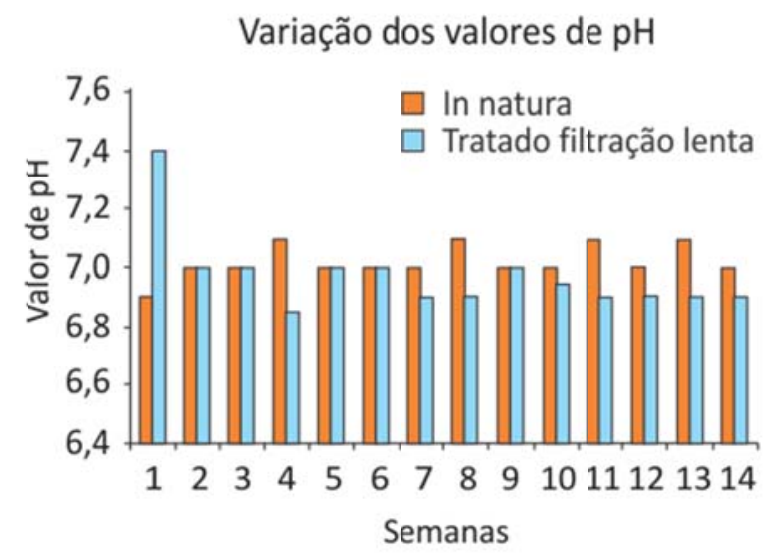

Figura 3: Estudo das médias dos valores de $\mathrm{pH}$ nas amostras não filtradas (In natura) e nas amostras filtradas (Tratado filtração lenta) referente ao mês de Fevereiro-2010.

De acordo com o gráfico apresentado os resultados estão dentro da faixa considerada ótima para o desenvolvimento dos micirorganismos necessária para a formação da camada de "shmutzdecke" no topo da coluna de areia e para o bom desenvolvimento do filtro lento.

Pode-se verificar que o $\mathrm{pH}$ variou de 6,7 a 7,4, encontrando-se dentro dos limites estabelecidos pela Resolução Conama no 357/2005 para corpos de água doce de Classe II $(6,0$ a 9,0) e estabelecidos pela Portaria MS 2914 de 2011 referente à potabilidade $(6,0$ a 9,5).

\subsection{Turbidez}

A turbidez em águas é causada geralmente pela presença de partículas em suspensão e colóides, derivados de argila, lama, matéria orgânica e inorgânica finamente dividida, plâncton e outros organismos microscópicos (OLIVEIRA, et al., 2008). O gráfico da Figura 4 apresenta os resultados do parâmetro de turbidez para as análises das amostras da água "in natura" e da água tratada pelo processo de filtração lenta. 
Análise dos valores de Turbidez

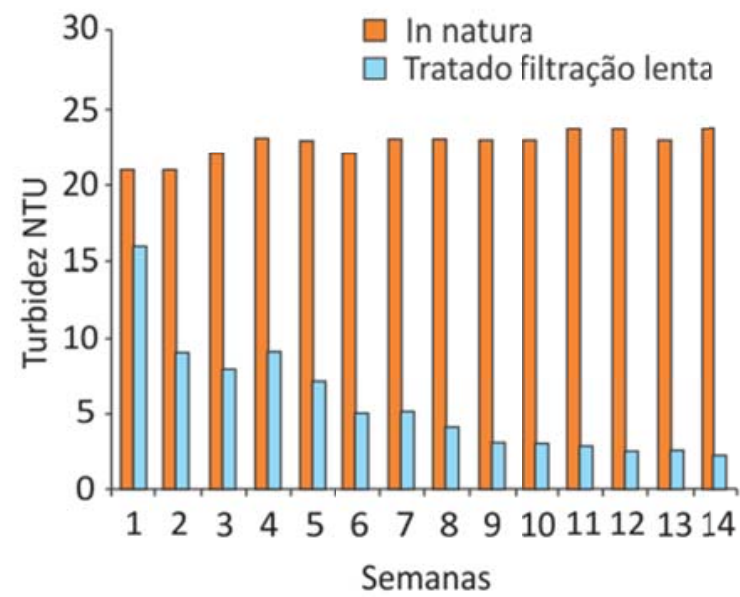

Figura 6: Estudo das médias dos valores de Oxigênio Consumido na amostra não filtrada (In natura) e na amostra filtrada (tratado filtração lenta) referente ao mês de Fevereiro-2010.

A área específica do material em suspensão é elevada e as partículas podem acomodar uma grande quantidade de poluentes e até microrganismos patogênicos, o que torna de suma importância à determinação deste parâmetro.

O padrão permitido pela resolução Conama $n$. 357/2005 é de 40 NTU, estabelecido para águas de classe 1 e para potabilidade segundo a Portaria do MS 2914 de 2011 é de 5,0 NTU. Neste estudo pode se observa uma redução da turbidez na faixa de $90 \%$ após sistema de filtração lenta.

\subsection{Coloração}

A cor pode ser altamente interferente nos processos fotossintéticos naturais nos leitos dos rios provocando alterações na biota aquática, principalmente se o corpo d'água receber descargas industriais (Brito e Paterniani, 2006).

A resolução Conama no 357/2005 estabelece

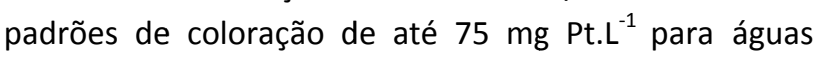
doces de classe 2 . Neste estudo a coloração fica bem abaixo deste valor tanto para amostra não filtrada como para a amostra filtrada (Figura 5).

\subsection{Matéria Orgânica}

Neste estudo diminuições da concentração de matéria orgânica foram encontradas na ordem de $50 \%$. Reduções similares foram encontradas com o emprego de métodos biológicos combinados com coagulação química seguido de oxidação por elétron fenton (Figura 6) (Lin e Chang, 2000).
Análise dos valores de Coloração

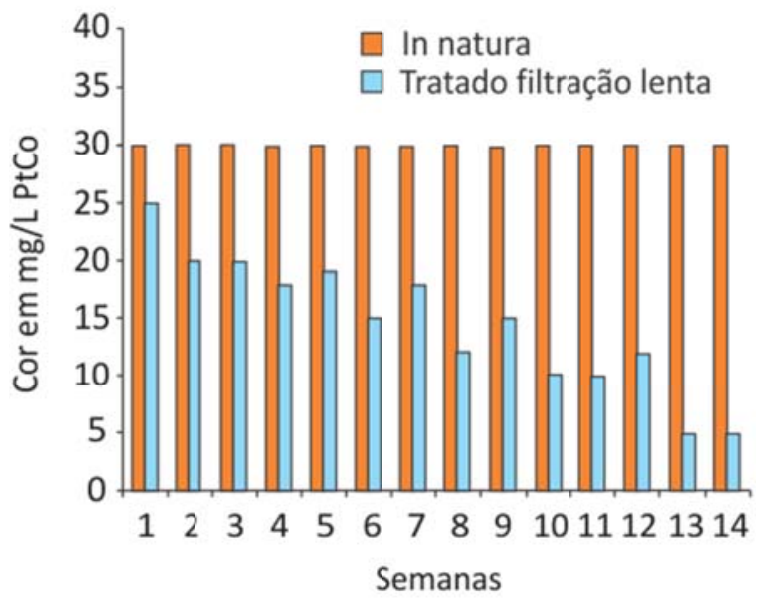

Figura 5: Estudo das médias dos valores de Cor na amostra não filtrada (In natura) e na amostra filtrada (tratado filtração lenta) referente ao mês de Fevereiro2010.

Análise dos valores de Matéria Orgânica

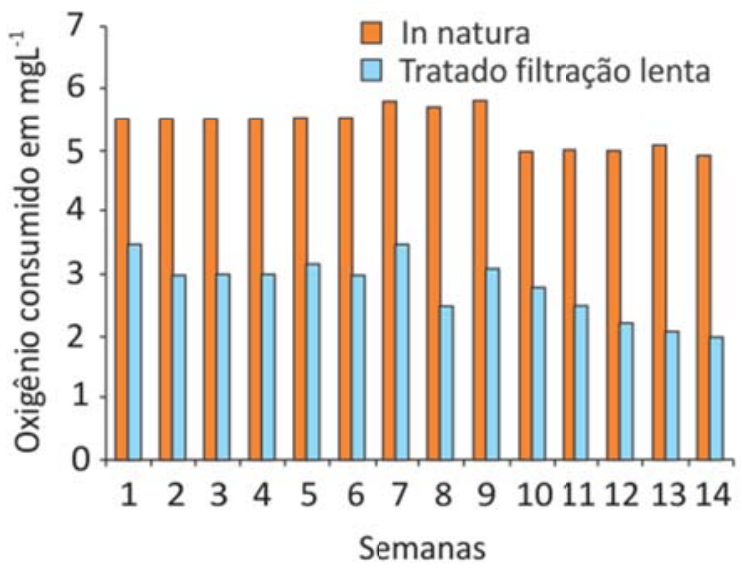

Figura 6: Estudo das médias dos valores de Oxigênio Consumido na amostra não filtrada (In natura) e na amostra filtrada (tratado filtração lenta) referente ao mês de Fevereiro-2010.

\subsection{Fenóis}

O fenol (ácido carbólico, ácido fênico) goza da dupla distinção de ter sido usado por Lister, durante os anos de 1860, em seus trabalhos sobre o desenvolvimento das técnicas de cirurgia asséptica, e de ser o padrão contra o quais outros desinfetantes são avaliados em sua ação bactericida. Embora sejam ainda popular, muitos outros desinfetantes recentes são muito mais eficazes e ativos em concentrações mais baixas. 0 fenol e alguns derivados, provavelmente atuam primariamente pela desnaturação das proteínas celulares e pelo dano das membranas celulares. Alguns 
deles, especialmente o hexilresorcinol, reduzem grandemente a tensão superficial, e esta propriedade contribui, indubitavelmente, para sua ação antimicrobiana (Pelczar, et al., 1980).

Neste estudo não foi detectado concentrações de fenóis totais na amostra "in natura"

\section{CONCLUSÕES}

De acordo com os parâmetros de qualidade da água "in natura" e tratada observados das análises realizadas, no período de quatro meses de monitoramento de funcionamento do filtro experimental ficou evidenciado que a amostra em estudo referente à lagoa de dentro do Centro de Ciências Agrárias (CCA) apresenta-se em boas condições. Demonstrando capacidade para realizar o ciclo de minerais importantes e que o filtro lento construído demonstra eficiência no polimento da matriz em estudo.

Assim o sistema avaliado mostrou-se com potencial para a utilização no tratamento de água de pequenas comunidades rurais.

\section{AGRADECIMENTOS}

Os autores agradecem ao Conselho Nacional de Pesquisa Científica - (CNPq) pela bolsa concedida.

\section{REFERÊNCIAS BIBLIOGRÁFICAS}

ABNT - Associação Brasileira de Normas Técnicas, NBR 9898: Preservação e técnicas de amostragem de efluentes líquidos e corpos receptores, Rio de Janeiro, 1987.

AMERICAN PUBLIC HEALTH ASSOCIATION-APHA. Standard Methods for the Water and Wastewater. 20 ed. New York: APHA (1998).

BRASIL. Conselho Nacional do Meio Ambiente. Resolução no 357, de 17 de março de 2005. Dispõe sobre uma nova classificação para as águas doces, bem como para as águas salobras e salinas do território nacional. Brasília: Conama, 2005.

BRITO, N.N. e PATERNIANI, J.E.S. Sistema de Filtração Lenta no Tratamento de Percolado do Aterro Sanitário de Limeira-SP. 77p. Dissertação (Mestrado). Faculdade de Engenharia Agrícola, Universidade de Campinas (UNICAMP), 2006.

CONSELHO NACIONAL DO MEIO AMBIENTE. 2005. Resolução CONAMA № 357. 2005.

LIN, S. H. e CHANG, C. C. Treatment of landfill leachate by combined electron-fenton oxidation and sequencing bath reactor method. Water Research, 34: (17) 4243-4249 (2000).
OLIVEIRA, V.M. e PELEGRINI, R.T. Avaliações Físicas, Químicas e Biológicas da Microbacia do Córrego Modeneis em LimeiraSP. Revista Engenharia Ambiental: Pesquisa e Tecnologia. 5:(1) 86-96, (2008).

PELCZAR, M.; REID, R. e CHAN, E.C.S. Microbiologia. São Paulo: Editora McGraw-Hill Ltda, Volume 1, 1980.

MS - Ministério da Saúde Portaria № 2914, de 12 de dezembro de 2011. Estabelece os procedimentos e responsabilidades relativos ao controle e vigilância da qualidade da água para consumo humano e seu padrão de potabilidade e dá outras providências. 2011.

VERAS, L.R.V.; DI BERNARDO, L. Tratamento de água de abastecimento por meio da tecnologia de filtração em múltiplas etapas- FIME. Engenharia Sanitária e Ambiental, vol. 13, n. 109-116, 2008. 